\title{
Correlation between Major Suitability, Peer Support, Major Satisfaction, and Caring Efficacy of Nursing Students
}

\author{
Jeong Sook Kim ${ }^{1}$, Nam Joo Je ${ }^{2 *}$, and Meera Park ${ }^{3}$ \\ ${ }^{1}$ Department of Nursing, JinJu Health College, Korea \\ ${ }^{2 * 3}$ Department of Nursing Changshin University, Korea \\ ${ }^{1}$ sook707kr@naver.com,2*jnj4757@cs.ac.kr, ${ }^{3}$ minerva32@cs.ac.kr
}

\begin{abstract}
This study was conducted to investigate on the correlation between major suitability, peer support, major satisfaction, and caring efficacy of nursing students. The data was collected from 181 nursing college students in J city from October 1st to October 21th, 2020. The instrument consisted of 73 items, measuring general characteristics, major suitability, peer support, major satisfaction, and caring efficacy. The data collected were analyzed using frequency (percentage), t-test, one-way analysis of variance, and Pearson correlation coefficient with IBM SPSS WIN/21.0. Major suitability had a positive correlation with peer support, major satisfaction, and caring efficacy. Peer support had a positive correlation with major satisfaction and caring efficacy. It is believed that an educational program using peer support groups will be helpful to improve major satisfaction and caring efficacy, and it is necessary to provide customized programs according to the degree of major suitability. The results of this study can be used as basic data in developing educational programs that help nursing students improve their adaptation and work performance at school or work. In addition, in order to generalize the research, it is suggested that various researches be conducted by adding a wide range of subjects and variables in the future by supplementing the limitations of this research.
\end{abstract}

Keywords: Caring efficacy, Nursing college students, Major satisfaction, Major suitability, Peer support

\section{Introduction}

\subsection{Significance}

The majority of college students in Korea become college students without enough time to explore their identity, interests, suitability and potential career paths due to the entrance examination-oriented education. Unlike their time in middle and high school, college students are asked to study by themselves in their learning environment and at the same time adjust to it. Under these circumstances, college students often experience maladjustment, dropout or contemplate about changing their major due to the discordance of major-aptitude and difficulty in choosing their career path [1]. Especially for nursing major, students often enter a nursing college based on external factors such as employment rate, recommendations and their high school grades rather than interned factors such as interest or aptitude [2]. The amount of study to be done in nursing major makes it more difficult for the students, affecting their major adaptation and satisfaction. Major satisfaction is the result of a good understanding of oneself

Article history:

Received (February 2, 2021), Review Result (February 28, 2021), Accepted (April 3, 2021) 
and the working world in which one can achieve one's desire. When major satisfaction is high, positive values for the nursing profession can be formed [3]. Nursing is based on the ability to take care of others, build a therapeutic relationship with patients and caring efficacy to provide professional nursing and make clinical decisions. Since caring efficacy can provide comfort and confidence in forming relationships with patients and performing tasks [4], efforts to improve caring skills in nursing education are essential [5]. Peer support was found to contribute to better adaptation in a study with nursing students [6], making it also considered as a variable that can improve nursing students' caring efficacy. However, it is difficult to generalize the results of precedent studies to nursing students due to the inconsistency in results or subjects, so it is necessary to understand the relationship between the variables. Therefore, the results of this study can be used as basic data in developing educational programs that can help the adaptation and performance of nursing students at school or workplace.

\subsection{Purpose}

"Are there any relationships among nursing college students' major suitability, peer support, major satisfaction, and caring efficacy?" The purpose of this study is to understand the degree and correlation of major suitability, peer support, major satisfaction, and caring efficacy in nursing students across all grade levels.

\section{Research method}

\subsection{Research design}

The following research was designed as a descriptive survey research to grasp the degree and relations between major suitability, peer support, major satisfaction and caring efficacy of nursing students.

\subsection{Research subjects}

Subjects were nursing students in J city, G-do who understood the purpose of the study and consented. Convenience sampling was made with exclusion of other majors. Using the program G*power 3.10 [7] with the effect size .30 (medium effect), significance level $(\alpha) .05$ and statistical power (1- $\beta$ ) .95 , correlation analysis was conducted to calculate sample size. The minimum number of individuals with an appropriate sample size was calculated as 134, but 184 people were initially sampled in anticipation of a high dropout rate. Of these, 181 samples were used for the final analysis, excluding 3 copies with poor responses.

\subsection{Research instrument}

A structured questionnaire was used in the following research, consisting a total of 73 questions that measure general characteristics (8 questions), major suitability (8 questions), peer support (9 questions), major satisfaction (18 questions), and caring efficacy (30 questions).

The general characteristics were measured by a total of 8 questions including age, gender, religion, circle activity, living environment, character, last semester rating and conflict experiences with reference to previous studies [8].

For major suitability, 3 questions measuring individual-job suitability from Park [9] who revised the scale from precedent studies [10][11][12] and 5 questions measuring individualmajor suitability from Kristof [13], Seong et al., [14] and the revision by Cho et al., [15] were used. The knowledge, skills, and abilities required to carry out their major perceived by a 
college student and the knowledge, skills, and abilities perceived by a college student correspond to each other. The instrument is on a Likert 5-point scale, with high score meaning better major suitability. Cronbach's $\alpha=.90$ in Park [9] and Cronbach's $\alpha=.74$ in the following research.

For peer support, the Student Social Support Scale (SSSS) developed by Nolten [16], edited by Lee [17] and revised by Lee [18] was used. The instrument is a total of 9 questions on a Likert 5-point scale, with high score meaning better peer support. Cronbach' $\alpha=.92$ in Lee [18] and Cronbach' $\alpha=.93$ in the following research.

For major satisfaction, From the instrument by Ha [19], the 18 questions related to major satisfaction chosen by Lee [20] were used to measure major satisfaction. The instrument is on a Likert 5-point scale, with high score meaning better major satisfaction. Cronbach's $\alpha=.90$ in Lee [20] and Cronbach' $\alpha=.92$ in the following research.

For caring efficacy, the caring efficacy scale developed by Coates [21] and revised for nursing students by Jeong [22] was used. The instrument is a total of 30 questions, each on a Likert 6-point scale with high score meaning better caring efficacy. Cronbach's $\alpha=.88$ at the time of development, Cronbach's $\alpha=.92$ in Jeong [22] and Cronbach' $\alpha=.94$ in the following research.

\subsection{Data collection period and method}

Data were collected from October $1^{\text {st }}$ to $31^{\text {st }}, 2020$. Hand sanitization and temperature checks were performed in compliance with the COVID-19 prevention guidelines and both the subjects and the researcher secured a separation distance with KF-94 masks on. The researcher explained the purpose of the study, anonymity guarantee and the research procedure to the subjects. In order to protect the subject's autonomy, rights and interests, documented consents were written for the research participation, the questionnaires were distributed only to subjects who provided the documented consent and they were asked to answer in a self-written manner. After the questionnaire was completed, anonymity was maintained by placing the consent form and questionnaire in separate envelopes and putting them in separate collection boxes.

\subsection{Ethical considerations}

Subjects who expressed voluntary participation were notified of the purpose of the study, confidentiality, and promise to destroy data, and that there was no disadvantage if they did not participate, and it was implemented after receiving written consent. It took about 20 to 30 minutes to fill out the questionnaire, and when the questionnaire was completed, the consent form and explanation were collected, put in an envelope, and collected by the researcher. A small gift in return was provided as a sign of appreciation to the subjects participating in the study.

\subsection{Data analysis}

The collected data were analyzed using IBM SPSS WIN/21.0. The significance level for the result was set to .05 and the reliability of the measurement instrument was calculated. The individual characteristics of the subject were identified by frequency (percentage). The mean and standard deviation were calculated for major suitability, peer support, major satisfaction, and caring efficacy. Differences in major suitability, peer support, major satisfaction, and caring efficacy according to the subject's characteristics were measured by t-rest and one-way 
ANOVA. Pearson's correlation coefficient was calculated for the correlation between major suitability, peer support, major satisfaction, and caring efficacy.

\subsection{Results}

\subsubsection{Characteristics of Subjects}

As for the age, '21-25 years old' was the largest with 116 people (64.1\%). For gender, 154 $(85.1 \%)$ were women and $27(14.9 \%)$ were men with the majority being women. 'None and Others' was highest with 118 people $(65.2 \%)$ in religion, followed by 'Buddhism' with 32 people (17.7\%). Most subjects did not participate in any circle activity (70.2\%). 'Living with parents' was the most with 94 people $(51.9 \%)$ in living environment. For character, 'Mixed' answered most with 111 people (61.3\%). 103 people (56.9\%) had over 3.5 in their last semester rating. For conflict experiences, 'Sometimes/Frequent' was the most with 93 people (51.4\%).

\subsubsection{Major suitability, peer support, major satisfaction and caring efficacy}

The average score for major suitability was 3.41 points (out of 5), peer support was 4.02 points (out of 5), major satisfaction was 3.72 points (out of 5) and caring efficacy was 4.32 (out of 6).

\subsubsection{Major suitability, peer support, major satisfaction and caring efficacy according to characteristics of subjects}

Major suitability showed a significant difference by age $(\mathrm{F}=4.41, \mathrm{p}=.002)$. Post-hoc verification revealed that 'over 41' group showed better major suitability than '21-25 years old' group. For last semester rating, 'over 3.5' showed better major suitability $(\mathrm{t}=-2.61, \mathrm{p}=.010)$.

Peer support showed a significant difference by living environment $(\mathrm{F}=2.66, \mathrm{p}=.049)$, but post-hoc verification returned with no significance. The 'over 3.5' group showed better peer support in last semester rating $(\mathrm{t}=-2.08, \mathrm{p}=.039)$. Age had a significant difference over major satisfaction $(\mathrm{F}=4.53, \mathrm{p}=.002)$. The result of post-hoc verified that 'over 41' group had higher major satisfaction than '21-25 years old' group. Living environment had a significant difference in major satisfaction initially $(\mathrm{F}=3.74, \mathrm{p}=.012)$, but post-hoc analysis showed no significance. Character had a significant difference in major satisfaction $(\mathrm{F}=3.23, \mathrm{p}=.042)$ and post-hoc analysis returned with 'Extrovert' group having higher major satisfaction than 'Introvert' group. Last semester rating showed higher major satisfaction in 'over 3.5' group ( $\mathrm{t}=-2.70$, $\mathrm{p}=.007)$.

Caring efficacy showed a significant difference by age $(\mathrm{F}=4.50, \mathrm{p}=.002)$. Post-hoc analysis verified that 'Under 20' group had better caring efficacy than '21-25 years old' and '26-30 years old' group. Male had better caring efficacy than women $(\mathrm{t}=3.28, \mathrm{p}=.001)$. Character had a significant difference $(\mathrm{F}=4.23, \mathrm{p}=.016)$ with the post-hoc showing that 'Extrovert' group having better caring efficacy than 'Introvert' group.

\subsubsection{Correlations among major suitability, peer support, major satisfaction and caring efficacy}

Major suitability had positive correlations with peer support $(\mathrm{r}=.53, p<.001)$, major satisfaction $(\mathrm{r}=.72, p<.001)$ and caring efficacy $(\mathrm{r}=.51, p<.001)$. Peer support had positive correlations with major satisfaction $(\mathrm{r}=.62, p<.001)$ and caring efficacy $(\mathrm{r}=.52, p<.001)$. Major satisfaction had a positive correlation with caring efficacy $(\mathrm{r}=.54, p<.001)$ [Table 1]. 
Table 1. Correlation among the research variables $(\mathrm{N}=181)$

\begin{tabular}{|c|c|c|c|c|}
\hline & Major suitability & Peer support & Major satisfaction & Caring efficacy \\
\hline & \multicolumn{4}{|c|}{$\mathrm{r}(\mathrm{p})$} \\
\hline Major suitability & 1 & & & \\
\hline Peer support & $.53(<.001)$ & 1 & & \\
\hline Major satisfaction & $.72(<.001)$ & $.62(<.001)$ & 1 & \\
\hline Caring efficacy & $.51(<.001)$ & $.52(<.001)$ & $.54(.001)$ & 1 \\
\hline
\end{tabular}

\section{Conclusions}

The purpose of this study was to correlate with the degree of major suitability, peer support, major satisfaction, and caring efficacy in nursing students across all grade levels. Major suitability had positive correlations with peer support, major satisfaction and caring efficacy in this study. Peer support had positive correlations with major satisfaction and caring efficacy. Major satisfaction had a positive correlation with caring efficacy. It is believed that students who chose nursing major due to external factors such as employment rate, recommendations and their high school grades have low major suitability which led to difficulty adjusting. Therefore, providing customized programs to those who experience difficulty in academic achievement based on their major suitability is needed. Educational programs using peer support group will be of help in providing extracurricular programs based on the academic needs and improving major satisfaction and caring efficacy of nursing students. The results of this study can be used as basic data in developing educational programs that help nursing students improve their adaptation and performance at school or workplace. For generalization, conducting additional studies which supplement the limitations of this research with a wider range of subjects and variables are recommended.

\section{References}

[1] Korean Educational Development Institute, "A study on university education system improvement in response to changing educational environment: Exploring strategies for building a customized education system," Report, (2014)

[2] J. W. Lee, N. Y. Lee, Y. S. Eo, "Path analysis of major satisfaction, clinical competence, career decisionmaking self-efficacy, and career decision level in undergraduate nursing students," Journal of the Korea Academia - Industrial cooperation Society, (2018), vol.19, no.1, pp.311-320, DOI: 10.5762/KAIS.2018.19.1.311

[3] J. H. Seo, "Effects of nursing image, satisfaction in major," Ego-Resilience on Nursing Professionalism of Nursing Students, Master' thesis, Kongju National University, (2018)

[4] C. Reid, M. Courtney, D. Anderson, C. Hurst, "The caring experience: Testing the psychometric properties of the caring efficacy scale," International Journal of Nursing Practice, (2014), vol.21, no.6, pp.904-912. DOI: 10.1111/ijn.12327

[5] S. G. Kim, E. S. Do, "Effect of emotional intelligence caring efficacy and resilience on satisfaction on clinical practice in nursing students," Journal of the Korea Academia-Industrial cooperation Society, (2019), vol.20 no.8, pp.231-239, DOI: 10.5762/KAIS.2019.20.8.231 
[6] S. Carroll, "Resiliency as a factor in the successful completion of a California community college based associate degree in nursing program," Doctoral Dissertation, California Lutheran University, California, (2011)

[7] F. Faul, E. Erdfelder, A. Buchner, A. G. Lang, "Statistical power analyses using G* Power 3.1: Tests for correlation and regression analyses," Behavior research methods, (2009), vol.41, no.4, pp.1149-1160, DOI: 10.3758/BRM.41.4.1149

[8] S. Y. Park. "Development and validation of the college life adjustment instrument for nursing students," Doctor's Dissertation, Dankook University, (2017)

[9] J. A. Park, "The effect of self-determination and personal-major fit of college students on adjustment to college: Analysis of the admission type and major of the department, Master' thesis, Ewha Womans University, (2019)

[10] D. M. Cable, D. S. DeRue, "The convergent and discriminant validity of subjective fit perceptions," Journal of Applied Psychology, (2002), vol.87, no.5, pp.875-884

[11] K. J. Lauver, A. Kristof-Brown, "Distinguishing between employees' perceptions of person job and person organization fit," Journal of Vocational Behavior, (2001), vol.59, no.3, pp.454-470

[12] M. Kim, Y. Shin, C. W. Moon, "Perceived person-job fit and task and contextual performance: The moderating effects of task significance and autonomy," Korean Journal of Management, (2012), vol.20, pp.93-128

[13] A. L. Kristof, "Person organization fit: An integrative review of its - conceptualizations, measurement, and implications," Personnel Psychology, (1996), vol.49, no.1, pp.1-49

[14] J. Y. Seong, W. W. Park, S. Yun, "The effect of person-environment (organization, supervisor, coworker) fit, on organizational citizenship behavior and performance, and the mediating effect of justice," Korean Journal of Management, (2008), vol.16, no.2, pp.1-62

[15] Y. H. Cho, J. C. Jung, M. Moon, "The effects person-university fit (PUF), person-major fit (PMF) on employability and educational achievement: The role of learning flow as a mediator," Mentoring as A Moderator, Korean Journal of Business Administration, (2013), vol.26, no.3, pp.749-780

[16] M. R. Lee, "A study on the social support system to influence on the high school students' adaptation to school life,” Master's Thesis, Taegu University, (2001)

[17] D. Y. Lee, "The mediating effect of depression in the influence of nursing college student's university life stress on adaption to college and moderated mediating effect of peer support," Inje University, (2020)

[18] P. W. Nolten, "Conceptualization and measurement of social support: The development of the student social support scale,” Doctoral Dissertation, University of Wisconsin, Madison, WI, (1994)

[19] H. S. Ha, “A study of department satisfaction and school satisfaction of undergraduate students," Master' Thesis, Seoul National University, (2000)

[20] D. J. Lee, "The relationships among satisfaction in major, gender identity, and gender stereotypes of male nursing students," Master' Thesis, Yensei University, (2004)

[21] C. J. Coates, “The caring efficacy scale: Nurses' self-reports of caring in practice settings," Advanced Practice Nursing Quarterly, (1997), vol.3, no.1, pp.53-59

[22] M. R. Jung, E. Jeong, "Effects of academic stress, academic self-efficacy and major satisfaction in nursing student on grit," Journal of the Korea Contents Association, (2018), vol.18, no.6, pp.414-423, DOI: 10.5392/JKCA.2018.18.06.414 


\section{Authors}

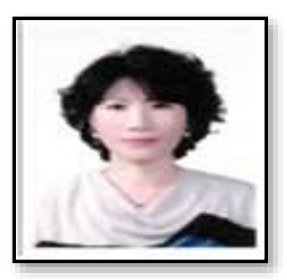

Jeong Sook Kim, RN, PhD

Associate Professor

Department of nursing, Jinju Health College, Jinju

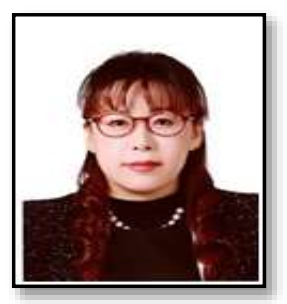

\section{Nam Joo Je, RN, PhD}

Associate Professor

Department of nursing, Changshin University, Changwon

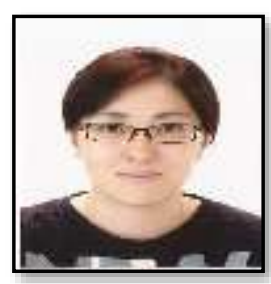

\section{Meera Park}

Assistant Professor

Department of nursing, Changshin University, Changwon 


\section{This page is empty by intentions.}

